\title{
Age- and sex-based variation in helminth infection of helmeted guineafowl (Numida meleagris) with comments on Swainson's spurfowl (Pternistis swainsonif) and Orange River francolin (Scleroptila levaillantoides)
}

\author{
Owen R. Davies ${ }^{1}$, Kerstin Junker ${ }^{2}$, Raymond Jansen ${ }^{3}$, Timothy M. Crowe $^{1^{\star}}$ \& \\ Joop Boomker ${ }^{2}$ \\ ${ }^{1} D S T / N R F$ Centre of Excellence, Percy FitzPatrick Institute, Department of Zoology, University of Cape Town, \\ Private Bag X3, Rondebosch, 7701 South Africa \\ ${ }^{2}$ Department of Veterinary Tropical Diseases, University of Pretoria, Private Bag X04, Onderstepoort, 0110 South Africa \\ ${ }^{3}$ Department of Environmental, Water and Earth Sciences, Tshwane University of Technology, \\ Private Bag X680, Pretoria, 0001 South Africa \\ Received 7 April 2008. Accepted 20 August 2008
}

\begin{abstract}
Gastrointestinal tracts from 48 helmeted guineafowl (Numida meleagris), five Swainson's spurfowl (Pternistis swainsonii) and a single Orange River francolin (Scleroptila levaillantoides) were examined for helminth parasites. Twelve species of helminths were found in helmeted guineafowl, comprising six nematodes, five cestodes and a single acanthocephalan. Six species of nematodes were recovered from Swainson's spurfowl and a single nematode was recovered from the Orange River francolin. First-year guineafowl had more than twice the intensity of infection than did adult guineafowl, particularly regarding the acanthocephalan Mediorhynchus gallinarum, the caecal nematodes Subulura dentigera and S. suctoria, and the cestodes Octopetalum numida, Hymenolepis cantaniana and Numidella numida. Female guineafowl had significantly higher intensities of infection than males, especially concerning $\boldsymbol{M}$. gallinarum, $\boldsymbol{S}$. dentigera and $\boldsymbol{N}$. numida and the nematode Gongylonema congolense. The recovery of the cestode Retinometra sp. from helmeted guineafowl constitutes a new host-parasite record.
\end{abstract}

Key words: gastrointestinal helminths, Numida meleagris, Pternistis swainsonii, Scleroptila levaillantoides.

\section{INTRODUCTION}

The helmeted guineafowl (Numida meleagris) is a terrestrial gamebird endemic to Africa (Crowe et al. 1986). It ranges throughout much of sub-Saharan Africa, occurring from Senegal in the west to Somalia in the east and extending southwards to South Africa, being absent only from forest, desert and high altitude regions (Crowe et al. 1986). Currently, nine subspecies are recognized from Africa (Crowe 1978). Historically in South Africa, its natural habitat included thorny scrub, savanna, grassland and other open country biomes, but habitat modification through agriculture and urbanization has resulted in an expansion of its range more than any gamebird in southern Africa

\footnotetext{
*To whom correspondence should be addressed.
}

E-mail: timothy.crowe@uct.ac.za
(Crowe 2000). Even though its natural range is restricted to Africa, it has been domesticated and bred widely on a commercial basis in, for example, France, Hungary, Italy, the United Kingdom, the United States of America, Australia and Russia (Haziev \& Khan 1991).

Because of the commercial value of guineafowl and the practice of free-range chicken farming in regions where guineafowl co-occur, studies on the parasites of guineafowl and their potential to infect chickens, and vice versa, have been undertaken in Mozambique (Cruz e Silva 1971; cited by Verster \& Ptasinska-Kloryga 1987), Ghana (Hodasi 1976), Nigeria (Ayeni et al. 1983) and Russia (Haziev \& Khan 1991). In southern Africa, various authors have investigated the helminth parasites of guineafowl, but many findings have been incidental. Ortlepp 
(1937, 1938a,b, 1963) studied helminths of guineafowl from various parts of southern Africa that were present in the then Onderstepoort Helminthological Collection or supplied by collectors (Verster \& Ptasinska-Kloryga 1987, Junker et al. 2008). Saayman (1966) recorded helminth burdens of guineafowl in the Eastern Cape Province, and Crowe (1977) collected 206 gastrointestinal tracts ('GITs' hereafter) from this host in savanna and riverine habitats in the Northern Cape Province, South Africa. Crowe (1977) reported first-year birds to have higher levels of helminth infection than adults, which he attributed to a greater intake of arthropod intermediate hosts by first-year birds and their lower resistance to infection. He also found no significant difference between males and females regarding helminth infections and suggested that this may be due to the lack of dietary, physiological and behavioural sexual dimorphism in the nonbreeding season, and called for an investigation of sexual variation in helminth infection before and during the breeding season, when such a dimorphism exists.

This study aims to determine whether levels of helminth infection differ with respect to the sex and age of guineafowl in a variegated agricultural habitat in the vicinity of Petrus Steyn $\left(27^{\circ} 39^{\prime} \mathrm{S}\right.$; $28^{\circ} 8^{\prime} \mathrm{E}$ ), Free State, and to add to the current paucity of helminth parasite data for guineafowl and other galliforms in South Africa (Junker et al. 2008).

\section{METHODS}

Forty-eight helmeted guineafowl, comprising 42 adults ( 23 males and 19 females) and six first-year birds (two males and four females), as well as five adult Swainson's spurfowl (Pternistis swainsonii) (one male and four females), and a single adult male Orange River francolin (Scleroptila levaillantoides) were collected during a commercial shoot on 4 August 2007. Each bird was weighed, sexed and examined macroscopically for gross pathological condition, e.g. emaciation, excessive feather loss, heavy ectoparasite infestation and tissue damage. Subsequently birds were dissected and their GITs removed. The crop, proventriculus, gizzard, small intestine, caecae and colon were tied off with dental floss to prevent the migration of parasites. GITs were fixed and stored in $70 \%$ ethanol and transported to the Department of Veterinary Tropical Diseases, University of Pretoria, for processing.

\section{Helminth collection}

The complete GITs were placed in a dissecting tray and each section dissected from the others at the point at which they were tied off. Each section was opened, scraped and rinsed over a $150 \mu \mathrm{m}$ sieve to collect helminths. Sieve contents were transferred into vials containing $70 \%$ ethanol. In addition, all parts of the GITs were examined under a dissecting microscope to recover helminths that had remained behind. The horny lining of the gizzard was peeled back and examined under a dissecting microscope.

For identification under a compound microscope, nematodes were cleared in lactophenol, and cestodes and acanthocephalans in Hoyer's medium. Nematodes from the crop, proventriculus and gizzard, as well as acanthocephalans from the small intestine were identified and counted individually. Nematodes from the caecae and cestodes from the small intestine were too numerous to be counted, and therefore a 1/10th aliquot of the entire sample of helminths was taken from which estimates were derived. To test the validity of this method, 10 such aliquots were taken from a preliminary sample containing a known number of helminths. The 1/10th aliquots estimated the number of helminths and species composition to within $95 \%$ of the known number in all 10 replicates. Aliquots were taken by bubbling air through a suspension of helminths in a $1500 \mathrm{ml}$ beaker to ensure homogeneity, and removing $150 \mathrm{ml}$ of the suspension with a large-diameter pipette.

In hosts where a certain cestode was represented by proglottids, but scoleces were absent, the parasite was recorded as 'present' only.

\section{Data analysis}

Data were collected for age, sex and body mass, and as these contained both categorical variables (age and sex) and a continuous variable (body mass) an ANCOVA was performed. A Bonferroni correction post-hoc test was used in order to avoid Type I errors as several statistical tests were performed simultaneously (Howell 1998). All statistical analyses were calculated using STATISTICA version 7.0 (StatSoft 2007).

The ecological terms prevalence, intensity of infection and mean intensity are used in accordance with Bush et al. (1997), where prevalence is defined as the number of hosts infected with one or more of a particular parasite species divided by the number of hosts examined and expressed as a percentage. Mean intensity is the average intensity 


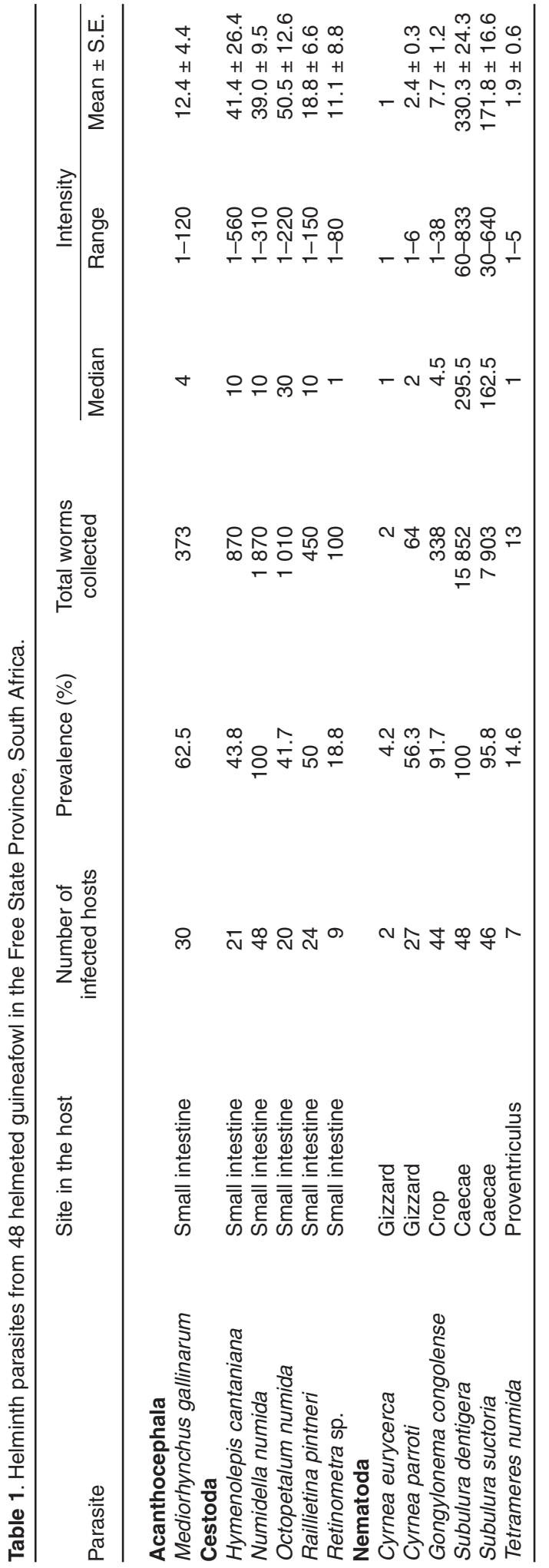

of a particular species of parasite among the infected members of a particular host species or category (i.e. sex or age). Intensity is the number of individuals of a particular parasite species in a single infected host.

Hosts in which only proglottids of a specific cestode were found were omitted from the calculations for mean intensity of the parasite.

\section{RESULTS}

All guineafowl, spurfowl and the single francolin harboured helminth parasites. A total of six nematode species, a single acanthocephalan and five cestode species were collected from the guineafowl hosts (Table 1). Swainson's spurfowl harboured six species of nematodes (Table 2). Two of the six species of nematodes recovered from these hosts were absent in guineafowl. A single nematode, Cyrnea eurycerca, was recovered from under the gizzard lining of the Orange River francolin.

A total of 28845 helminths was collected from the guineafowl and the intensity of infection ranged from 122 to 2025, with a mean intensity of 601. Intensity of infection in Swainson's spurfowl was comparatively low, ranging from three to 68 . Only 95 helminths were recovered from the spurfowl with a mean intensity of 19 .

All 48 guineafowl harboured at least two helminth species. Both the nematode Subulura dentigera and the cestode Numidella numida were the most prevalent helminths in guineafowl each with a prevalence of $100 \%$. The second most prevalent helminth was the nematode S. suctoria, followed by the nematode Gongylonema congolense, the acanthocephalan Mediorhynchus gallinarum, the cestodes C. parroti, Raillietina pintneri, Hymenolepis cantaniana, Octopetalum numida, Retinometra sp., and the nematodes Tetrameres numida, and $C$. eurycerca (Table 1, 3).

Mean intensity of each helminth species per guineafowl category is summarized in Table 4.

None of the birds showed any signs of gross pathological condition. There was also no significant association between body mass and intensity of infection (ANCOVA $P=0.41$ ), but there was a significant association between sex and intensity of infection $(P<0.001)$, and between age and intensity of infection $(P<0.001)$.

After pooling all helminth species, the mean intensity was more than twice as high in first-year guineafowl than in adults (d.f. $=11$, 


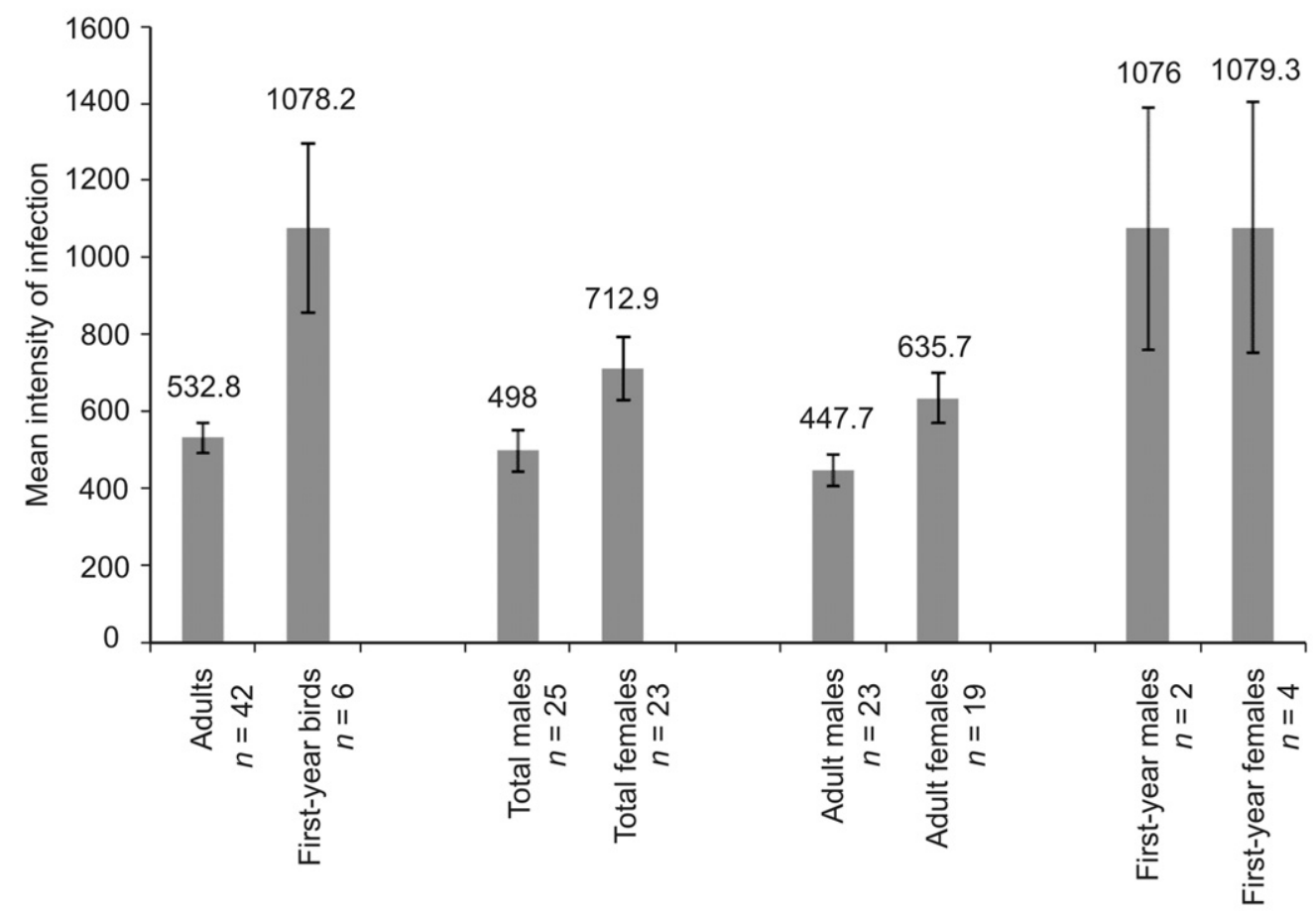

Fig. 1. Mean intensity of infection of each host category of helmeted guineafowl. Helminth species have been pooled in this graph.

$t=-2.66, P=0.011$ ) (Fig. 1), and females had significantly higher mean intensities of infection than males (d.f. $=31, t=2.41, P=0.011$ ) (Fig. 1).

Bonferroni post-hoc analysis showed that intensity of infection with $G$. congolense, S. dentigera, M. gallinarum and $N$. numida differed with host gender (d.f. $=43$ ), and intensity of infection. Infection by Subulura dentigera, S. suctoria, M. gallinarum, $O$. numida, $H$. cantaniana and $N$. numida differed with respect to host age (d.f. $=43$ ). The interaction of sex and age together was significantly correlated with different intensities of G. congolense, S. dentigera, S., suctoria, M. gallinarum, $O$. numida, $H$. cantaniana and $N$. numida.

Intensity of infection with $G$. congolense was higher in female guineafowl than in males $(P<$ $0.001)$, and females had higher intensities of S. dentigera $(P=0.002)$, M. gallinarum $(P=0.01)$ and $N$. numida $(P=0.015)$ than males.

First-year guineafowl had higher intensities of infection with $M$. gallinarum $(P<0.001)$, S. dentigera $(P=0.09)$, S. suctoria $(P=0.038), O$. numida $(P<0.001), H$. cantaniana $(P=0.01)$ and $N$. numida $(P<0.001)$ when compared with adult birds.

\section{DISCUSSION}

Levels of helminth infection in helmeted guineafowl examined during this study were generally low in comparison with those recorded by other authors (Crowe 1977; Verster \& Ptasinska-Kloryga 1987; Junker et al. 2008). This is especially true with respect to the cestodes, and may be a result of two factors. Firstly, the studies of Crowe (1977) and Junker et al. (2008) were conducted in natural habitats. The guineafowl examined in this study were collected within a variegated agricultural landscape, where the greater use of pesticides and other methods of pest control may have resulted in a reduced abundance of arthropod intermediate hosts. It has also been suggested that a reduction in landscape level biodiversity (such as moving from natural to agricultural habitats) may result in the reduction of intermediate host diversity and consequently lower the prevalence of some parasite species (Van Buskirk \& Ostfeld 1998; Ostfeld \& Keesing 2000), or indeed a shift in the parasite host relationship (Horwitz \& Wilcox 2005). Secondly, guineafowl examined for this study were collected in winter. Mentis et al. (1975) and Prinsloo et al. (2008) showed that the winter diet of these birds consists mainly of 
Cyperus corms and wheat, with grass seeds and grass leaves also occurring in the winter diet. Maize was shown to be particularly prevalent in the diet of guineafowl collected during winter, with arthropods occurring in very low numbers (Mentis et al. 1975; Prinsloo et al. 2008). Saayman (1966) also found low incidence of insects in guineafowl diet during winter. Additionally, Little et al. (1993) showed that cestode infection in greywing francolin (Scleroptila africanus) was lowest in winter and also attributed this to their seasonally variable diet.

The intensity of infection in Swainson's spurfowl was even lower when compared to the guineafowl, and only nematodes were recovered from these hosts. This observation may be due to the different social habits of spurfowl, in that they live in pairs or small family groups (Jansen \& Crowe 2002), in contrast to guineafowl that generally form large stable flocks of between 15 and 40 birds (Crowe 2000). In a study of bobwhite quail (Colinus virginianus), Moore et al. (1988) showed that birds from large coveys had significantly higher levels of helminth infection than did birds from small coveys. Crowe (1977) suggested that larger guineafowl flocks produce more droppings at higher densities, e.g. at communal roosts. A higher dropping density would increase the probability of arthropod intermediate hosts in the area ingesting dung contaminated with helminth eggs. These arthropods would therefore have a higher chance of becoming infected, as well as being ingested by guineafowl as flock size increases, because the foraging efficiency on prey species increases as a function of group size (Moore et al. 1988). Swainson's spurfowl is smaller than helmeted guineafowl, and some studies suggest that the prevalence and biomass of intestinal parasites scales positively with host body mass (Poulin \& George-Nascimento 2007). However, we do not think that this can explain the observed differences between the two species as this only holds true for the maximum biomass of parasites that a host can harbour (Poulin \& George-Nascimento 2007). Furthermore the hosts in this study had comparably low levels of infection as mentioned above.

Various studies on host age and sex in relation to intestinal helminths in other galliform birds have shown mixed results. Davidson et al. (1977) reported that juvenile ruffed grouse (Bonasa umbellus) in the United States had higher intensities of infection than adults, whereas Moore et al. (1987) showed that there was no significant difference between age or sex regarding intensities of infection in bobwhite quail. Little et al. (1993) also found no significant difference between age and sex classes in the prevalence of helminth infection in greywing francolin. This study conforms with Crowe (1977) in that first-year guineafowl had higher intensities of infection than adults but, unlike Crowe's (1977) findings, female guineafowl in this study had significantly higher intensities of infection than males. Female guineafowl had significantly higher intensities of the nematodes $G$. congolense and S. dentigera, the acanthocephalan $M$. gallinarum and the cestode $N$. numida. Higher infection of these helminths in females may be a legacy of feeding on more arthropods during the previous breeding season than males, in order to bulk up in protein necessary for egg-laying during the breeding season (Crowe 2000). Hodasi (1976) suggested that the intermediate hosts of $M$. gallinarum are grasshoppers. Crowe (2000) also noted that during courtship, males may forego feeding to catch grasshoppers and drop them in front of females. Alternatively, Prinsloo (2003) showed that female guineafowl have significantly longer small intestines and caecae than males, thus providing a larger habitat for the helminths to colonize. Studies looking at sex-based differences in parasite infection of other vertebrate hosts have revealed that males generally have higher levels of parasite infection than females. This trend has been attributed to: sex-based hormones (Folstad \& Karter 1992, Poulin 1996, Klein 2004), where it was shown that androgen and testosterone have an immunosuppressive effect. Also, differences might be due to behaviour; Ezenwa (2004) for example, showed that male African bovids became more susceptible to infection after courtship displays and defending females, reducing their nutritional intake and overall dietary scope, and male sticklebacks were more likely than females to consume copepods, a cestode intermediate host (Reimchen \& Nosil 2001). This study represents one of few examples of a female bias in parasite infection (McCurdy et al. 1998, Christe et al. 2007), and provides ecological factors such as male behaviour, and the resultant dietary differences of female helmeted guineafowl as explanations.

First-year guineafowl had significantly higher intensities of infection with the acanthocephalan $M$. gallinarum, the nematodes $S$. dentigera and S. suctoria, and the cestodes $O$. numida, $H$. cantaniana and $N$. numida than did adults (Table 4). The higher intensities of infection in first-year birds may 
also be attributed to dietary differences between first-year birds and adults, since arthropods form a greater proportion of the diet of first-year birds (Crowe 2000). Higher intensities of helminth infection in first-year birds may also be due to their lower resistance to infection (Biester \& Schwarte 1959). Soulsby (1969) suggested that juvenile domestic fowl have lower resistance to helminth infection due to an insufficiency of antibodies necessary for preventing infection. Gastrointestinal helminths may also exert a selective pressure on first-year birds, in that those that are more susceptible to helminth infection and therefore acquire higher helminth burdens than their contemporaries, could suffer higher mortality. In this way, adult birds may show a lower level of infection merely as a result of the fact that first-year birds with low resistance did not reach maturity, but were removed from the population.

Similar to gender-related differences in intensity of infection, the higher intensities in first-year birds could be a result of first-year birds having significantly longer small intestines and caecae than adults (Prinsloo 2003).

This study presents the first record of the genus Retinometra in helmeted guineafowl.

\section{ACKNOWLEDGEMENTS}

We thank J.P. Wales for access to 'The Jimmy Wales Shoot' to collect gastrointestinal tracts. This research was supported financially by the Centre of Excellence at The Percy FitzPatrick Institute (funded by the South African Department of Science and Technology and The National Research Foundation) and the University of Cape Town's Research Committee.

\section{REFERENCES}

AYENI, J.S.O., DIPEOLU, O.O. \& OKAEME, A.N. 1983. Parasitic infections of the grey-breasted helmet guinea-fowl (Numida meleagris galeata) in Nigeria. Vet. Parasitol. 12: 59-63.

BIESTER, H.E. \& SCHWARTE, L. (Eds) 1959. Diseases of poultry, 4th edn. Iowa State College Press, Ames.

BUSH, A.O., LAFFERTY, K.D., LOTZ, J.M. \& SHOSTAK, A.W. 1997. Parasitology meets ecology on its own terms: Margolis et al. revisited. J. Parasitol. 83: 575-583.

CHRISTE, P., GLAIZOT, O., EVANNO, G., BRUYNDONCKX, N., DEVEVEY, G., YANNIC, G., PATTHEY, P., MAEDER, A., VOGEL, P. \& ARLETTAZ, R. 2007. Host sex and ectoparasites choice: preference for, and higher survival on female hosts. J. Anim. Ecol.76: 703-710.

CROWE, T.M. 1977. Variation in intestinal helminth infestation of the helmeted guineafowl. S. Afr. J. Wildl. Res. 7: 1-3.
CROWE, T.M. 1978. The evolution of guineafowl (Galliformes, Phasianidae, Numidinae): taxonomy, phylogeny, speciation and biogeography. Ann. S. Afr. Mus. 78: 43-136.

CROWE, T.M. 2000. Helmeted guineafowl. In: R.M Little \& T.M. Crowe (Eds), Gamebirds of southern Africa (pp. 90-95). Struik, Cape Town.

CROWE, T.M., KEITH, G.S. \& BROWN, L.H. 1986. Galliformes. In: E Urban, C.H. Fry \& G.S. Keith (Eds), Birds of Africa Vol. II (pp. 1-75). Academic Press, London.

CRUZ E SILVA, J.A. 1971. Contribuição para o estudo dos helmintes parasitas dos vertebrados de Moçambique. Mem. Junta Invest. Ultram. 61: 1-479.

DAVIDSON, W.R., DOSTER, G.L., PURSGLOVE, S.R. \& PRESTWOOD, A.K. 1977. Helminth parasites of ruffed grouse (Bonasa umbellus) from the eastern United States. Proc. Helminthol. Soc. 44: 156-161.

EZENWA, V. 2004. Interactions among host diet, nutritional status and gastrointestinal parasite infection in wild bovids. Int. J. Parasitol. 34: 535-542.

FOLSTAD, I. \& KARTER, A.J. 1992. Parasites, bright males, and the immunocompetence handicap. $A m$. Nat. 139: 316-318.

HAZIEV, G.Z. \& KHAN, S.A. 1991. Helminths of guineafowl (Numida meleagris) in Bashkir ASSR. Vet. Parasitol. 38: 349-353.

HODASI, J.K.M. 1976. The helminth parasites of the helmet guinea fowl (Numida meleagris galeata pallas) in Ghana. Bull. Anim. Hith. Prod. Afr. 24: 81-87.

HOWELL, D.C. 1998. Statistical methods for psychology, 4th edn. Brooks/Cole Publishing.

HORWITZ, P. \& WILCOX, B.A. 2005. Parasites, ecosystems and sustainability: an ecological and complex systems perspective. Int. J. Parasitol. 35: 725-732.

JANSEN, R. \& CROWE, T.M. 2002. Population fluctuations in relation to seasional habitat preferences of Swainson's spurfowl, Pternistis swainsonii. Afr J. Ecol. 40: 309-317.

JUNKER, K., DEBUSHO, L. \& BOOMKER, J. 2008. The helminth community of helmeted guineafowls, Numida meleagris (Linnaeus, 1758), in the north of Limpopo Province, South Africa. Onderstepoort J. Vet. Res. 75: 225-235.

KLEIN, S.L. 2004. Hormonal and immunological mechanisms mediating sex differences in parasite infection. Para. Immun. 26: 247-264.

LITTLE, R.M., VERSTER, A. \& CROWE, T.M. 1993. Seasonal and demographical variation in intestinal helminth infection of greywing francolin. Ostrich 64: 178-181.

McCURDY, D.G., SHUTLER, D., MULLIE, A. \& FORBES, M.R. 1998. Sex-biased parasitism of avian hosts: relations to blood parasite taxon and mating system. Oikos 82: 303-312.

MENTIS, M.T.B., POGGENPOEL, B. \& MAGUIRE, R.R.K. 1975. Food of helmeted guineafowl in highland Natal. J. S. Afr. Wildl. Manage. Assoc. 5: 23-25

MOORE, J., SIMBERLOFF, D. \& FREEHLING, M. 1988. Relationships between bobwhite quail social-group size and intestinal helminth parasitism. Am. Nat. 131: 22-32.

ORTLEPP, R.J. 1937. South African helminths. Onderste- 
poort J. Vet. Sci. Anim. Ind. 9: 311-336.

ORTLEPP, R.J. 1938a. South African helminths. Some mammalian and avian cestodes. Onderstepoort $\mathrm{J}$. Vet. Sci. Anim. Ind. 11: 23-50.

ORTLEPP, R.J. 1938b. South African helminths. Some avian and mammalian helminths. Onderstepoort $\mathrm{J}$. Vet. Sci. Anim. Ind. 11: 63-104.

ORTLEPP, R.J. 1963. Observations on cestode parasites of guineafowl from southern Africa. Onderstepoort J. Vet. Res. 30: 95-118.

OSTFELD, R.S. \& KEESING, F. 2000. Biodiversity and disease risk: the case of Lyme disease. Conserv. Biol. 14: 722-728.

POULIN, R. 1996. Sexual inequalities in helminth infections: A cost of being a male? Am. Nat. 147: 287-295.

POULIN, R. \& GEORGE-NASCIMENTO, M. 2007. The scaling of total parasite biomass with host body mass. Int. J. Parasitol. 37: 359-364.

PRINSLOO, H.C. 2003. An investigation into factors influencing the abundance of helmeted guineafowl (Numida meleagris) in the Reimland of the northeastern Free State, South Africa. Unpubl. M. Tech. dissertation, Department of Nature Conservation, Technikon Pretoria.
PRINSLOO, H.C., HARLEY, C., REILLY, B. \& CROWE, T.M. 2008. The diet of helmeted guineafowl (Numida meleagris) in the Riemland of the north-eastern Free State, South Africa. S. Afr. J. Wildl. Res. 38(1): 88-92.

REIMCHEN, T.E. \& NOSIL, P. 2001. Ecological causes of sex-biased parasitism in three-spined stickleback (Gasterosteus aculeatus). Bio. J. Linn. Soc. 73: 51-63.

SAAYMAN, J. 1966. A study of the diet and parasites of Ardeola (Bubulcus) ibis, Numida meleagris and Gallus domesticus from the Eastern Cape Province, South Africa. Ph.D. dissertation, University of South Africa.

SOULSBY, E.J.L. 1969. Helminths, arthropods, and protozoa of domesticated animals. Baillière, Tindall and Cassell, London.

STATSOFT (Inc.) 2007. Statistica computational software version 7.0. Tulsa, O.K. (www.statsoft.com).

VAN BUSKIRK, J. \& OSTFELD, R.S. 1998. Habitat heterogeneity, dispersal, and local risk of exposure to Lyme disease. Ecol. Appl. 8: 365-378

VERSTER, A. \& PTASINSKA-KLORYGA, Y. 1987. Helminths of helmeted guineafowl in southern Africa. S. Afr. J. Wild. Res. Suppl. 1: 36-38.

Corresponding Editor: M.I. Cherry 